\title{
АДАПТАЦИЯ ДЕЯТЕЛЬНОСТИ ТАМОЖЕННЫХ ОРГАНОВ В УСЛОВИЯХ СНИЖЕНИЯ ПЕРЕЧИСЛЕНИЙ ТАМОЖЕННЫХ ПЛАТЕЖЕЙ
}

\begin{abstract}
Аннотация. Предметом исследования является современные механизмы административной деятельности таможенных органов в условиях снижения в 1,6 раз поступлений таможенных платежей в бюджет. Автором проведен анализ мероприятий таможенных органов по повышению собираемости таможенных платежей. В статье обращено внимание на неэффективность осуществляемых проверок, рост их количества, проведения проверок по направлениям, потерявшим актуальность и не дающим желаемых результатов. В работе проведен количественный и качественный анализ результатов контрольных мероприятий после выпуска товаров. Методологическую основу составили общефилософский и теоретический методы. Для формулирования частных выводов применялся системный подход, метод моделирования и сравнения статистических данных. Для оценки эффективности управления деятельностью таможенных органов применен закон Парето. Научная новизна статьи заключается в системном анализе деятельности таможенных органов в условиях снижения активности внешнеэкономической деятельности и уменьшения объемов перечислений таможенных платежей. Автором предложено совершенствование деятельности таможенных органов осуществлять в тех направлениях, в которых можно достичь максимальных результатов: укрепление таможенных постов за счет дебюрократизации таможен и управлений, отказ от старых, неэффективных контрольных мероприятий, переход к выборочному таможенному контролю на основе системы управления рисками, упрощение таможенного тарифа
\end{abstract}

Ключевые слова: Таможенное право, Таможенные платежи, Закон Парето, адаптация, дебюрократизация, таможенные посты, таможенная проверка, контрольная деятельность, эффрективность, система управления рисками.

Abstract. The research subject is the modern mechanisms of administrative activities of customs bodies in the context of 1.6 times decrease in customs payments. The author analyzes the steps taken by customs authorities to increase the customs payments collection rate. The author pays attention to the inefficiency of inspections, the increase of their number, the fact that inspections are carried out in the spheres which have lost their importance and are not effective. The paper contains quantitative and qualitative analysis of the results of inspections upon the release of goods. The research methodology is based on general scientific and theoretical methods. The author applies the system approach, modeling and statistical data comparison. To assess the effectiveness of customs bodies management, the author applies the Pareto principle. The author carries out the system analysis of customs bodies' activities in the context of the decreased foreign trade and the amounts of customs payments. The author proposes to improve customs bodies' activities in those spheres where the maximum results can be achieved: the strengthening of customs stations via debureaucratization of customs and departments, abandoning old and inefficient control activities in favor of selective customs control based on the risks management system, and the reduction of customs tariff.

Key words: risks management system, effectiveness, control activity, customs inspection, customs stations, debureaucratization, adaptation, Pareto principle, customs payments, customs law.

$\Pi$ о итогам 2014 года Федеральная таможенная служба перечислила в федеральный бюджет 7746 млрд. рублей [1]. Вклад таможенных органов в кассовом исполнении бюджета составил 53\% и являлся наибольшей долей таможенных платежей в истории современной России.

В 2015 году перечисления Федеральной таможенной службы в федеральный бюджет снизились до 4911 млрд. рублей [2]. При прогнозируемом общем объеме доходов федерального бюджета на 2015 год в 13251 млрд.рублей [3], доля Федеральной таможенной службы в исполнении бюджета составит около 37\%. Сумма перечисленных в бюджет платежей значительно снизилась, но с точки зрения состояния экономики, снижение доли таможенных платежей в общем объеме собираемых доходов является положительным моментом, поскольку свидетельствует об уменьшении доли, получаемой от продажи сырьевых товаров и роста поступлений в бюджет за счет налогов, т.е. внутреннего производства в стране.

Вместе с тем, снижение перечислений таможенных платежей почти в полтора раза стало очень заметным явлением для таможенных орга- 
нов. Также необходимо учесть, что таможенные платежи в большинстве случаев, рассчитываются исходя из адвалорных ставок пошлины, т.е. зависящей от таможенной стоимости товаров. В свою очередь, стоимость товаров берется из внешнеторговых контрактов, заключенных, как правило, в иностранной валюте. Основной валютой во внешнеторговых контрактах являются доллары США и Евро, как более стабильные и подверженные меньшим курсовым колебаниям валюты, в сравнении с денежными единицами других стран. По данным Центрального Банка РФ индекс номинального курса рубля к доллару США за 2015 год снизился на 37,4\% в сравнении с 2014 годом, а индекс номинального курса рубля к евро за этот же период снизился на 25,2\% [4]. Учитывая, что таможенные платежи исчисляются в рублях, рост курса доллара США и Евро к рублю ведет к увеличению объема собираемых платежей в рублях. Следовательно, при сохранении товарооборота и структуры перемещаемых через границу товаров на уровне 2014 года, объем перечисляемых таможенных платежей в бюджет должен был вырасти на треть. Однако этого не произошло, платежи в бюджет в абсолютном выражении упали в 1,58 раз, что свидетельствует о резком снижении объемов грузов, перемещаемых через границу [5].

В сложившихся экономических условиях и начавшихся изменениях структуры органов исполнительной власти [6] необходима адаптация работы таможенных органов по взиманию таможенных платежей в новых реалиях.

В таможенных органах основная доля таможенных платежей, перечисляемая в бюджет страны, собирается благодаря деятельности таможенных постов. Именно на этапе проверки таможенных деклараций, осуществления мероприятий таможенного контроля обеспечивается перечисление в бюджет максимальной доли таможенных пошлин, налогов, сборов и других платежей, взимание которых возложено на таможенные органы. Исходя из опубликованных ФТС России данных за 2015 год, из 4911 млрд. рублей, перечисленных в бюджет, свыше 18,5 миллиардов рублей довзыскано таможенными органами в доход бюджета по итогам проверочных мероприятий, которые были проведены в рамках работы по минимизации рисков нарушения таможенного законодательства до выпуска товаров и проведения таможенного контроля после их выпуска [7]. Таким образом, в результате добросовестного исполнения своих обязанностей участниками внешнеэкономической деятельности в 2015 году в бюджет перечислено 99,6\% собранных таможенных платежей. В результате дополнительной проверки деклараций таможенными органами в бюджет перечислено всего лишь 0,4\% от общей суммы перечислений таможенных платежей.

Контрольная деятельность таможенных органов по увеличению собираемости таможенных платежей осуществляется до выпуска товаров и после выпуска товаров. При проведении мероприятий таможенного контроля до выпуска товаров основную роль также играют таможенные посты, поскольку именно они осуществляют условный выпуск товаров, принимают обеспечение уплаты таможенных платежей при дополнительных проверках функциональными подразделениями таможни по направлениям контроля таможенной стоимости товаров, правильности классификации товаров в соответствии с товарной номенклатурой внешнеэкономической деятельности, определения страны происхождения товаров, соблюдения запретов и ограничений. В большинстве случаев именно таможенные посты на основе системы управления рисками выявляют необходимость проведения дополнительных мероприятий таможенного контроля и являются их инициаторами.

Ключевую роль при осуществлении таможенного контроля после выпуска товаров в таможенных органах играют отделы таможенного контроля после выпуска товаров. Именно эти подразделения проводят таможенные проверки по наиболее сложным категориям дел и крупным суммам предполагаемых доначислений таможенных платежей. Этому дополнительно способствуют установленные для таможенных органов контрольные показатели эффективности деятельности, в число которых входит сумма начисленных и взысканных таможенных платежей при проведении таможенных проверок. По результатам деятельности подразделений (отделов) после выпуска товаров в 2014 году в бюджет взыскано таможенных платежей, пеней и штрафов на сумму 2,9 млрд. рублей [8], что составило $0,04 \%$ от общей суммы доходов, администрируемых таможенными органами в 2014 году [9]. Определенный вклад в дополнительное взыскание таможенных платежей после выпуска товаров вносят также и другие функциональные подразделения, включая правоохранительный блок таможни, но эти суммы значительно ниже, чем у специализированного подразделения. Точный подсчет суммы дополнительного взыскания таможенных платежей после выпуска товаров, исходя из имеющихся данных затруднителен, поскольку некоторые суммы в связи с несовершенством методики расчета могут учитываться дважды и трижды. Положительные результаты проверок записывают себе в «достижения» все функциональные подразделения, в той или иной мере осуществлявших таможенный контроль после выпуска товаров: подразделения, выявившие нарушение таможенного 


\section{Административное и муниципальное право 9 (105) • 2016}

законодательства и передавшими материалы для проверки в подразделения таможенного контроля после выпуска товаров, сами подразделения таможенного контроля после выпуска товаров, по результатам проверок которых довзысканы таможенные платежи, правоохранительные подразделения таможни, оказывавшие содействие в проведении таможенной проверки.

Таким образом, в результате дополнительных проведенных мероприятий по увеличению собираемости таможенных платежей в бюджет взыскивается менее $1 \%$ от общей суммы администрируемых таможней платежей.

По приблизительным оценкам численность персонала в штате таможенных постов к общему служащих таможен составляет около 20\%. Например, в соответствии с Приказом ФТС России от 18 марта 2015 года № 467 «0 совершенствовании структуры таможенных органов, расположенных в Центральном федеральном округе» [10] с 25 июня 2015 года аннулируются действующие коды Ивановского, Кинешемского и Шуйского таможенных постов Ивановской таможни и присваиваются коды Ивановскому, Кинешемскому и Шуйскому таможенным постам Владимирской таможни. В результате мероприятий сокращено 124 единицы штатной численности Ивановской таможни, а штат Владимирской таможни будет дополнен 28 единицами штатной численности Ивановского, Кинешемского и Шуйского таможенных постов. Следовательно, штат таможенных постов Ивановской таможни составлял $28 / 124 * 100 \%=22 \%$ от общего штата таможни.

Исходя из произведенного анализа, можно заключить, что в таможенных органах перечисление в бюджет 99\% сумм таможенных платежей обеспечивается благодаря деятельности 20\% штатной численности таможен - таможенных постов. Конечно, деятельность таможенных постов не была бы столь результативной, если бы таможенные органы не осуществляли дополнительный таможенный контроль помимо того, что проводится на таможенном посту. Необходимо обязательно отметить, что дополнительные, результативные контрольные мероприятия «дисциплинируют» участников внешнеэкономической деятельности, побуждают их добросовестно исполнять свои обязанности и избегать занижения перечислений таможенных платежей в бюджет.

Для выработки предложений по повышению результатов деятельности таможенных органов по вопросам взимания таможенных платежей можно применить закон Парето. Закон Парето (принцип Парето), или правило 80/20 - один из наиболее распространенных способов оценки эффективности какой-либо деятельности. Его суть заключает- ся в том, что 20\% усилий дают $80 \%$ результата, а остальные $80 \%$ усилий реализуют лишь 20\%. Таким образом, можно понять, что, выбрав те оптимальные ресурсы, которые дают наибольший эффект, можно достичь высоких результатов малыми издержками. В то же время последующие усилия будут ненужными и неэффективными [11].

Поэтому целевым направлением, к которому должна двигаться таможенная служба на современном этапе - это приложение максимальных усилий к поиску повышения эффективности деятельности таможенных постов, поскольку именно деятельность постов дает максимальный результат.

Можно предложить следующие направления совершенствования деятельности таможенных органов в соответствии с законом Парето:

- у укрепление таможенных постов;

- отказ от неэффективных мероприятий таможенного контроля на современном этапе, главным образом на уровне таможен и управлений;

- перераспределение штатной численности таможенных органов в пользу таможенных постов за счет сокращения должностей в таможнях и управлениях, осуществляющих мероприятия, которые не увеличивают собираемость таможенных платежей или не дают реальные результаты. Нельзя назвать нормальной ситуацию со штатами, когда на каждую должность инспектора на таможенном посту, приходится по 4 штатной должности в таможне;

- повышение среднего уровня заработной платы на таможенном посту до среднего по таможне. Дифференциация средней заработной платы на таможенном посту и таможне объясняется тем, что на постах почти все должности составляют государственные гражданские служащие, а сотрудники таможенных органов в основном состоят в штатах таможни;

Предпосылкой перераспределения штатной численности должностных лиц от таможни в пользу таможенного поста должен стать отказ от тотальной контрольной проверки участников внешнеэкономической деятельности.

В связи с принятой программой по сокращению сроков совершения таможенных операций [12], таможенные органы применяют выборочный таможенный контроль в отношении перемещаемых через границу товаров. С этой целью в соответствии с п. 1 ст. 128 ТКТС таможенные органы применяют систему управления рисками для определения товаров, транспортных средств международной перевозки, документов и лиц, подлежащих таможенному контролю, форм таможенного контро- 
ля, применяемых к таким товарам, транспортным средствам международной перевозки, документам и лицам, а также степени проведения таможенного контроля. Применение системы управления рисками позволяет значительно сократить усилия таможенных органов по осуществлению мер таможенного контроля. В целом, отмечая положительный момент от применения системы управления рисками необходимо отметить и один из ее недостатков, сложившийся в российских условиях. Система оценки и управления рисками допускает разработку и реализацию таможенными органами практических мер в отношении конкретного субъекта, перемещающего товар через таможенную границу. Участники внешнеэкономической деятельности крайне не заинтересованы в срабатывании в отношении них профиля риска, поскольку это значительно увеличивает сроки таможенного декларирования, требует предоставления дополнительных документов, внесения обеспечения уплаты таможенных платежей. Поэтому, применение подобной практики в отношении «неугодных» участников внешнеэкономической деятельности ведет к нарушению принципа равенства участников внешнеэкономической деятельности, создает предпосылки для проявления коррупционных правонарушений, поскольку должностные лица, наделенные полномочиями утверждать профили риска, могут решать вопрос о включении или не включении лица, перемещающего товар через границу, в профиль риска.

В связи со значительным снижением объемов перечислений таможенных платежей в 2015 году в таможенных органах значительно увеличилось количество мероприятий, направленных на выявление резервов повышения собираемости таможенных платежей. Все это делается под лозунгом повышения эффективности администрирования собираемости таможенных платежей, усиление эффективности управления таможенными органами. Проводимые мероприятия можно разделить на две группы:

1) повторный таможенный контроль по выпущенным декларациям на товары;

2) планирование и проведение мероприятий по досрочному перечислению таможенных платежей в бюджет в текущем отчетном периоде, срок перечисления которых должен наступить в следующем периоде.

К первой группе относятся мероприятия по повторной проверке всех деклараций, по которым предоставлены льготы по уплате таможенных платежей, предоставлены тарифные преференции, усиление контроля таможенной стоимости, правильности классификации товаров и другие контрольные функции. Как уже отмечалось выше, в результате проведенных мероприятий дополнительно в доход взыскивается 0,04\% от общей суммы администрируемых доходов. Общее снижение товарооборота внешней торговли ведет к уменьшению перечислений таможенных платежей и снижению загруженности таможенных органов при оставшейся штатной численности почти на том же уровне. Поэтому органы управления, в т.ч. из за недостаточной квалификации, отсутствия новых подходов для проведения контрольных функций, для повышения “видимости” проводимой работы могут предложить только экстенсивные меры - увеличить количество старых мероприятий. В последнее время обозначился переход почти к 100\% проверке всех выпущенных деклараций на правомерность предоставленных льгот и преференций, правильности начисления и уплаты таможенных платежей, контроля таможенной стоимости товаров. По результатам дополнительно проведенных мероприятий таможенные органы обязаны предоставлять отчеты о проделанной работе. Добросовестное выполнение добавочных мероприятий возможно только при увеличении штатной численности, что вряд ли возможно в современных экономических условиях. Поэтому все эти мероприятия, как правило, остаются полностью выполненными только на бумаге и отнимают дополнительное время и ресурсы на отчеты, соответственно уменьшая время на реальный контроль. При этом, устаревшие мероприятия, которые уже стали неэффективны или потеряли свою актуальность не отменяются т.к. руководители не могут принять не популярное решение - снизить количество мероприятий, направленных на повышение собираемости таможенных платежей.

Вторая группа мероприятий относится к поиску резервов перечислений таможенных платежей, но фактически не увеличивает перечисления в бюджет таможенных платежей, а направлена на сдвиг сроков перечисления таможенных платежей в бюджет на несколько дней в конце отчетного периода. Создается видимость увеличения поступлений в бюджет суммы таможенных платежей в текущем периоде. Однако сумма таможенных платежей в следующем периоде уменьшится на эту же сумму. По сути, эти мероприятия позволяют увеличить продолжительность отчетного квартала (месяца) на несколько дней за счет сокращения следующего квартала. Подобными мероприятиями создается цепная реакция. В конце следующего периода для перечисления в бюджет, как правило, не хватает суммы, которая была перечислена досрочно в предыдущем периоде. Чтобы выполнить план в наступившем, «урезанном» периоде необходимо «залезать в долг» в следующий период. Современная реальность такова, что эти мероприятия стали по- 


\section{Административное и муниципальное право 9 (105) • 2016}

стоянными и обязательными. Данные мероприятия имеют и другие негативные последствия: снижается точность прогнозирования перечисления денежных средств, создаются новые, регулярно применяющиеся и не документированные правовыми актами правила перечисления денежных средств, принадлежащих участникам внешнеэкономической деятельности в бюджет, значительно снижается равномерность перечисления денежных средств в бюджет - огромные суммы поступают в конце отчетного периода, а в первые дни нового периода почти отсутствуют перечисления.

Полагаем, что выходом в условиях снижения перечислений таможенных платежей должно стать проведение ревизии всех проводимых таможенными органами мероприятий, с оценкой достигаемых результатов и затраченных ресурсов. Основным способом повышения эффективности взимания таможенных платежей должно стать проведение органам управления аналитической работы по выбору возможных объектов дополнительного контроля как это предусмотрено системой управления рисками. Вместо 10-30 проверок в месяц таможенного инспектора можно заставить выполнять и 1000 проверок, но вряд ли он проведет их реально, не поверхностно и результативно. Поэтому в основу количества анализируемых объектов должны стать обоснованные нормативы нагрузки на штатную должность.

В небольших таможнях, в связи с малым количеством оформляемых деклараций для создания адекватной загрузки должностных лиц проводящих таможенный контроль после выпуска товаров, возможно возложение на них обязанностей проведения контрольных мероприятий по декларациям, выпущенным в крупных таможнях другого региона. В условиях электронного декларирования товаров это сделать не трудно - необходимо наделить соответствующих должностных лиц полномочиями и предоставить им доступ к информации по декларированию в другой таможне со своего рабочего места.

Работа органов управления по повышению эффективности взимания таможенных платежей должна строиться на результативности проверки выбранных объектов для контроля. Необходимо повышать результативность работы качеством, а не количеством проведенных мероприятий. За основу планирования проводимых контрольных мероприятий должны стать достигнутые результаты деятельности проведению таможенного контроля после выпуска товаров в предыдущем году: количество проверенных организаций, деклараций, дополнительно начисленная сумма таможенных платежей, процент проигранных дел (решение по дополнительному взысканию таможенных плате- жей было отменено судом или отменено в порядке ведомственного контроля вышестоящим таможенным органом). Вне всякого сомнения, показатели деятельности предыдущих лет будут запаздывать в складывающейся тенденции увеличения или уменьшения объемов выполняемой работы, поскольку они фиксируют усредненные показатели за предыдущий период. Поэтому если наметилась тенденция на снижение или, наоборот, на рост объема перемещаемых грузов, то и показатели необходимо соответственно снижать или увеличивать в сравнении с предыдущим годом. Исходя из достигнутых показателей по количеству вынесенных решений и сумме доначислений, а также прогнозируемому проценту решений, вынесенными судами в пользу таможенных органов должно устанавливаться количество контрольных мероприятий и суммы доначислений на текущий год. Именно под это количество запланированных проверок должна проводиться аналитическая работа по выбору объектов для повторного контроля. Таможенные органы, по возможности, должны проводить мероприятия в пределах установленных значений и увеличивать их количество, если только они позволят улучшить установленные относительные показатели эффективности деятельности таможенных органов. Для объективной оценки результативности проводимого анализа при выборе объектов для таможенного контроля должны учитываться все повторно проверяемые декларации, а не только те, в отношении которых в последующем имеются довзыскания таможенных платежей. Оценка результатов контрольной деятельности должна производится не только в абсолютных значениях, а большей частью в относительных: процент доначислений в общем объеме проверенных деклараций и перечислений таможни, сравнение результатов с прошлым годом, количество отменных решений судом в т.ч. по актам проверки прошлых лет, количество проверенных участников внешнеэкономической деятельности, к общему количеству осуществляющих внешнеэкономическую деятельность. При сокращении количества участников внешнеэкономической деятельности в условиях снижения объемов внешней торговли даже сохранение количества проверок на уровне прошлого года ведет к увеличению нагрузки на предпринимателей, поскольку растет относительное количество «проверенных» таможней лиц т.е. государство все сильнее и сильнее контролирует бизнес.

Заслуживает внимание ограничение проводимых проверок после выпуска товаров потенциальной суммой, подлежащих доначислению таможенных платежей, например, не менее 100000 рублей с одной декларации. Это становится все более ак- 
туально в связи с ростом количества декларирования товаров профессиональными участниками таможенных правоотношений - таможенными представителями. Принятие данного предложения позволит ослабить давление на бизнес со стороны таможенных органов и избавит таможенные органы от мелочных доначислений таможенных платежей, стоимость затрат на проведение мероприятий которых (с учетом возможного последующего обжалования действий таможенных органов, возмещения издержек по проигранным делам) выше суммы доначислений.

Другим способом повышения эффективности работы по перечислению таможенных платежей может стать упрощение таможенного тарифа - свода ставок таможенных пошлин. В настоящее время отдельные участники внешнеэкономической деятельности для минимизации перечисляемых в бюджет таможенных платежей пытаются декларировать товары по смежным кодам товарной номенклатуры внешнеэкономической деятельности, по которым ставки пошлины меньше. ФТС России постоянно проводится работа по разъяснению порядка классификации товаров в соответствии товарной номенклатурой внешнеэкономической деятельности (ТН ВЭД). Однако в практической деятельности не является редкостью применение смежных кодов при классификации товаров (например витамины для животных классифицируются как кормовые добавки), позволяющих снизить размеры уплачиваемых таможенных платежей. Нередко такой «неправильной» классификации способствует сложившаяся судебная практика.

Значительному сокращению манипуляций с кодами ТН ВЭД может способствовать упрощение таможенного тарифа и установление ставки та- моженный пошлины на уровне первых 4 знаков ТН ВЭД. Кроме того, необходимо проведение постоянной работы по выявлению смежных кодов классификации товаров, позволяющих применять сниженные ставки пошлины и последующего принятия решений по унификации ставок по этим кодам ТН ВЭД. В этом случае точное значение кода ТН ВЭД будет важно для целей таможенной статистики, а необходимость подмены декларантом кода ТН ВЭД отпадет в связи с тем, что размер таможенной пошлины от этого меняться не будет.

Важнейшим направлением, позволяющим сделать процедуру таможенного декларирования более простой является упрощение таможенных процедур и правил заполнения таможенных деклараций. В связи со сложной и запутанной процедурой таможенного декларирования она становится не такой прозрачной и доступ к ней открыт только специалистам, круг участников таможенных правоотношений становится элитарным. Достаточно взглянуть на таможенные декларации, оформленные на один и тот же товар в Европейском Союзе и у нас, чтобы понять насколько сложнее процедура декларирования в России.

В целом, мы полагаем, что реформированием деятельности Федеральной таможенной службы в условиях снижения активности внешнеэкономической деятельности должна заниматься внешняя государственная структура, не входящая в структуру таможенных органов, которая способна рассмотреть и оценить ситуацию со стороны. Именно этот орган должен подготовить предложения по дебюрократизации аппарата управления таможенных органов в целях повышения эффективности контрольных мероприятий в современных, изменившихся условиях.

\section{Библиография:}

1. Федеральный закон от 05.10.2015 № 276-Ф3 «Об исполнении федерального бюджета за 2014 год» // Собрание законодательства РФ. 12.10.2015. № 41 (часть I). Ст. 5630 (Закон, прил. 1, 2, 3 (начало)), Собрание законодательства РФ, 12.10.2015, N 41 (часть II), ст. 5630 (прил. 3 (продолжение), 6 - 8).

2. ФТС России собрала 4,91 триллиона в федеральный бюджет // http://customs.ru/index.php?option=com content\&view=article\&id=22388:-491-\&catid=40:2011-01-24-15-02-45\&Itemid=2094\&Itemid=1835

3. Федеральный закон от 01.12.2014 № 384-Ф3 «О федеральном бюджете на 2015 год и на плановый период 2016 и 2017 годов» // Собрание законодательства РФ. 08.12.2014. № 49 (часть I). Ст. 6893 (Федеральный закон, приложения 1-8, приложение 11 (начало)), Собрание законодательства РФ. 12.2014. № 49 (часть II). Ст. 6893 (приложение 11 (окончание), приложение 14 (начало)), Собрание законодательства РФ. 08.12.2014. № 49 (часть III). Ст. 6893 (приложение 14 (окончание), приложение 16 (начало)), Собрание законодательства РФ. 08.12.2014. № 49 (часть IV). Ст. 6893 (приложение 16 (окончание), приложение 18, приложение 20 (начало)), Собрание законодательства РФ. 08.12.2014. № 49 (часть V). Ст. 6893 (приложение 20 (окончание), приложения 24, 27, 30, 31, $33,35,36,38-43)$.

4. Центральный банк РФ-Основные производные показатели динамики обменного курса рубля в 2015 году // http://www.cbr.ru/statistics/print.aspx?file=credit_statistics/ex_rate_ind_15.htm\&pid=svs\&sid=analit

5. По данным таможенной статистики в январе-ноябре 2015 года внешнеторговый оборот России составил $\$ 484,4$ млрд., что на 33,8\% меньше по сравнению с январем-ноябрем 2014 года. Экспорт России в январе-ноябре 2015 года составил \$316,6 млрд., по сравнению с январем-ноябрем 2014 года снизился на 31,6\%. Импорт России в январе-ноябре 2015 года составил \$167,8 млрд., по сравнению с январем-ноябрем 2014 года снизился на 37,5\%. // http://bonds.finam.ru/news/item/fts-vneshnetorgovyiy-oborot-rossii-za-yanvar-noyabr-2015-goda-snizilsya-na-33-8/ 


\section{Административное и муниципальное право 9 (105) • 2016}

6. Указ Президента РФ от 15.01.2016 №12 «Вопросы Министерства финансов Российской Федерации» // Официальный интернет-портал правовой информации http://www.pravo.gov.ru. 15.01.2016.

7. ФТСРоссии В 2015 году:цифрыифакты//http://customs.ru/index.php?option=com_content\&view=article\&id=22392:2015-\&catid=40:2011-01-24-15-02-45\&Itemid=2094\&Itemid=1835

8. Итоги деятельности таможенных органов по осуществлению таможенного контроля после выпуска товаров за 2014 год // http://customs.ru/index.php?option=com_content\&view=article\&id=20466:--------2014\&catid=343:2012-08-09-12-59-58\&Itemid=1830\&Itemid=2268

9. ФТС России собрала 7 триллионов рублей в федеральный бюджет // http://customs.ru/index.php?option=com content\&view=article\&id=20337:-7-\&catid=185:2011-05-15-14-11-59\&Itemid=1830\&Itemid=2099

10. Приказ ФТС России от 18 марта 2015 года № 467 «0 совершенствовании структуры таможенных органов, расположенных в Центральном федеральном округе» // http://www.customs.ru/index.php?option=com_content\&view $=$ article\&id=20712:2015-03-27-06-04-10\&catid=40:2011-01-24-15-02-45

11. Закон Парето-Правило 80/20 // http://constructorus.ru/uspex/zakon-pareto.html

12. Распоряжение Правительства РФ от 29.06.2012 № 1125-р «Об утверждении плана мероприятий ("дорожной карты") "Совершенствование таможенного администрирования"» // Собрание законодательства РФ. 2012. № 28. Ст. 3926

13. Галузо В.Н. О некоторых проблемах отраслевой принадлежности таможенных платежей в Российской Федерации // Финансовое право и управление. - 2014. - 3. - С. 140 - 143. DOI: 10.7256/2310-0508.2014.3.13719.

14. А.В. Мотин Проблемы совершенствования организационно- экономического механизма управления промышленным сектором уголовно- исполнительной системы // Полицейская деятельность. - 2012. - 1. - С. 5 - 8.

15. Свинухов В.Г., Сенотрусова С.В. Принуждение в сфере уплаты таможенных платежей // Финансовое право и управление. - 2015. - 2. - С. 208 - 212. DOI: 10.7256/2310-0508.2015.2.15757.

16. Галузо В.Н. О системе таможенных платежей в Российской Федерации // Финансовое право и управление. - 2014. - 4. - C. 271 - 274. DOI: 10.7256/2310-0508.2014.4.14475.

\section{References (transliterated):}

1. Federal'nyi zakon ot 05.10 .2015 № 276-FZ «Ob ispolnenii federal'nogo byudzheta za 2014 god» // Sobranie zakonodatel'stva RF. 12.10.2015. № 41 (chast' I). St. 5630 (Zakon, pril. 1, 2, 3 (nachalo)), Sobranie zakonodatel'stva RF, 12.10.2015, N 41 (chast' II), st. 5630 (pril. 3 (prodolzhenie), 6 - 8).

2. FTS Rossii sobrala 4,91 trilliona $\mathrm{v}$ federal'nyi byudzhet // http://customs.ru/index.php?option=com_ content\&view=article\&id=22388:-491-\&catid=40:2011-01-24-15-02-45\&Itemid=2094\&Itemid=1835

3. Federal'nyi zakon ot 01.12.2014 № 384-FZ «0 federal'nom byudzhete na 2015 god i na planovyi period 2016 i 2017 godov»// Sobranie zakonodatel'stva RF. 08.12.2014. № 49 (chast' I). St. 6893 (Federal'nyi zakon, prilozheniya 1-8, prilozhenie 11 (nachalo)), Sobranie zakonodatel'stva RF. 12.2014. № 49 (chast' II). St. 6893 (prilozhenie 11 (okonchanie), prilozhenie 14 (nachalo)), Sobranie zakonodatel'stva RF. 08.12.2014. № 49 (chast' III). St. 6893 (prilozhenie 14 (okonchanie), prilozhenie 16 (nachalo)), Sobranie zakonodatel'stva RF. 08.12.2014. № 49 (chast' IV). St. 6893 (prilozhenie 16 (okonchanie), prilozhenie 18, prilozhenie 20 (nachalo)), Sobranie zakonodatel'stva RF. 08.12.2014. № 49 (chast' V). St. 6893 (prilozhenie 20 (okonchanie), prilozheniya 24, 27, 30, 31, 33, 35, 36, 38-43).

4. Tsentral'nyi bank RF-Osnovnye proizvodnye pokazateli dinamiki obmennogo kursa rublya v 2015 godu // http://www. cbr.ru/statistics/print.aspx?file=credit_statistics/ex_rate_ind_15.htm\&pid=svs\&sid=analit

5. Po dannym tamozhennoi statistiki v yanvare-noyabre 2015 goda vneshnetorgovyi oborot Rossii sostavil $\$ 484,4$ mlrd., chto na 33,8\% men'she po sravneniyu s yanvarem-noyabrem 2014 goda. Eksport Rossii v yanvare-noyabre 2015 goda sostavil $\$ 316,6$ mlrd., po sravneniyu s yanvarem-noyabrem 2014 goda snizilsya na 31,6\%. Import Rossii v yanvarenoyabre 2015 goda sostavil $\$ 167,8$ mlrd., po sravneniyu s yanvarem-noyabrem 2014 goda snizilsya na 37,5\%. // http:// bonds.finam.ru/news/item/fts-vneshnetorgovyiy-oborot-rossii-za-yanvar-noyabr-2015-goda-snizilsya-na-33-8/

6. Ukaz Prezidenta RF ot 15.01.2016 №12 «Voprosy Ministerstva finansov Rossiiskoi Federatsii» // Ofitsial'nyi internetportal pravovoi informatsii http://www.pravo.gov.ru. 15.01.2016.

7. FTS Rossii v 2015 godu: tsifry i fakty // http://customs.ru/index.php?option=com_content\&view=article\&id=22392:2015-\&catid=40:2011-01-24-15-02-45\&Itemid=2094\&Itemid=1835

8. Itogi deyatel'nosti tamozhennykh organov po osushchestvleniyu tamozhennogo kontrolya posle vypuska tovarov za 2014 god // http://customs.ru/index.php?option=com_content\&view=article\&id=20466:-----------2014-\&catid=343:201208-09-12-59-58\&Itemid=1830\&Itemid=2268

9. FTS Rossii sobrala 7 trillionov rublei $\mathrm{v}$ federal'nyi byudzhet // http://customs.ru/index.php?option=com_ content\&view=article\&id=20337:-7-\&catid=185:2011-05-15-14-11-59\&Itemid=1830\&Itemid=2099

10. Prikaz FTS Rossii ot 18 marta 2015 goda № 467 «O sovershenstvovanii struktury tamozhennykh organov, raspolozhennykh $\mathrm{v}$ Tsentral'nom federal'nom okruge» // http://www.customs.ru/index.php?option=com_content\&view=article\& id=20712:2015-03-27-06-04-10\&catid=40:2011-01-24-15-02-45

11. Zakon Pareto-Pravilo 80/20 // http://constructorus.ru/uspex/zakon-pareto.html

12. Rasporyazhenie Pravitel'stva RF ot 29.06.2012 № 1125-r «Ob utverzhdenii plana meropriyatii ("dorozhnoi karty") "Sovershenstvovanie tamozhennogo administrirovaniya"» // Sobranie zakonodatel'stva RF. 2012. № 28. St. 3926

13. Galuzo V.N. O nekotorykh problemakh otraslevoi prinadlezhnosti tamozhennykh platezhei v Rossiiskoi Federatsii // Finansovoe pravo i upravlenie. - 2014. - 3. - C. 140 - 143. DOI: 10.7256/2310-0508.2014.3.13719.

14. A.V. Motin Problemy sovershenstvovaniya organizatsionno- ekonomicheskogo mekhanizma upravleniya promyshlennym sektorom ugolovno- ispolnitel'noi sistemy // Politseiskaya deyatel'nost'. - 2012. - 1. - C. 5 - 8.

15. Svinukhov V.G., Senotrusova S.V. Prinuzhdenie v sfere uplaty tamozhennykh platezhei // Finansovoe pravo i upravlenie. - 2015. - 2. - C. 208 - 212. DOI: 10.7256/2310-0508.2015.2.15757.

16. Galuzo V.N. O sisteme tamozhennykh platezhei v Rossiiskoi Federatsii // Finansovoe pravo i upravlenie. - 2014. - 4. C. 271 - 274. DOI: 10.7256/2310-0508.2014.4.14475. 